\title{
Heterogeneity of Data: Implications for a Variable Federal Grazing Fee
}

JOHN M. FOWLER, MARTIN BLAKE, AND L. ALLEN TORELL

Abstract

Average grazing lease prices as tabulated in the 1985 federal grazing fee review and evaluation study were found to be signifcantly different between some pricing regions of the study. Comparing the federal study with a New Mexico state land grazing fee study indicated that lease prices were not homogeneous, even within pricing regions. This heterogeneity of data indicates that a variable federal grazing fee structure should be established if welfare of public land ranchers and collecting full market value of public land forage is important. Other factors, such as ease of fee administration and strong political support have been important considerations in setting the current single uniform fee. The current single-fee formula that sets one uniform graxing fee for all western states cannot be statistically defended. If grazing fees were significantly increased using the current single-fee formula, or any other single-fee formula, an inequitable distribution of impacts upon public land ranchers would arise; some would be subsidized while others would likely be damaged.

The range livestock industry in the western United States is comprised of highly divergent components. Ranching operations vary according to managerial ability, financial structure, land ownership patterns, size, topography, range productivity, climate and type of livestock. In attempting to describe and analyze the ranching industry, many researchers inadvertently disguise existing variability through the process of aggregation. This article demonstrates the problems arising from inappropriate aggregation.

Researchers often use measures of central tendency and dispersion, such as the mean, median and standard deviation when dealing with large quantities of data. When these measures are calculated from individual observations with similar characteristios, these statistics accurately portray a typical group member and lead to policy prescriptions that are likely to be pertinent and accepted. However, if descriptive statistics are calculated from individual observations with dissimilar characteristics, these statistics often describe a typical group member that is not representative of any segment of the original population. These distorted research results often result in faulty inferences and can culminate in inappropriate policy formulation.

Aggregation of observations is involved in virtually every statistical procedure. Therefore, it is an accepted statistical procedure to test a group of individual observations for homogeneity before aggregation. This avoids misleading inferences. The rule of thumb is-if the data are homogeneous, aggregation is appropriate. If the data are heterogeneous, the data must first be stratified into groups with similar characteristics and statistical analysis performed on each separate group. ${ }^{1}$

The aggregation problem related to setting public land grazing fee policy was recognized 13 years ago by Nielsen (1972) based upon earlier 1966 federal grazing fee studies. Nielsen stated: "If permittees can be stratified into grazing fee market areas where their total cost differentials are more nearly homogeneous, the variation within each group or market area would be much less

\footnotetext{
Authors are associate professor, professor and assistant professor, Department of Agricultural Economics and Agricultural Business, New Mexico State University, Las Cruces, New Mexico, 88003 .

This publication is New Mexico Experiment Station Journal Article No. 1185.

Manuscript accepted 19 August 1985.
}

I Heterogeneity can be with respect to any of the 4 moments, i.e. mean, variance, skewness, and kurtosis; however, in this paper only the mean was tested. than when all permittees are grouped together. In addition, the government would come nearer its goal of collecting full market value in grazing fees"(Nielsen 1972, P. 5). Nielsen went on to argue that although the data were not adequate to determine the best variable fee system, they were sufficient to set variable fees that more closely approximated the governments' goals than did a single uniform fee. Obermiller (1984) pointed out the consensus among economists at the 1982 symposium on public lands grazing fees in New Orleans, Louisiana, was that a variable federal grazing fee system would be most equitable and desirable.

The 1966 federal grazing fee study did not support the definition of regional grazing fee pricing but rather recommended a single fee. The fixed fee concept has strong political support from the livestock ind ustry and also benefits from an administrative perspective due to ease and uniformity of application. The current federal grazing fee level was set by a formula developed under the Public Rangelands Improvement Act (PRIA) of 1978. The formula adjusts for beef prices, production costs, and private land forage lease rates. ${ }^{2}$

While a uniform fee, such as determined by the PRIA formula, has certain obvious adminstrative advantages, any fixed single fee, regardless of annual adjustment mechanism, does not adequately recognize that the value of public grazing varies across geographic areas and by type of livestock operation. If the fee is set too high then public land ranchers can be placed at a comparative disadvantage to the private land sector, and potential public land grazing resources could go unused. If the level is set too low, public land ranchers are subsidized and realize a comparative advantage to the private sector.

\section{Results and Discussion}

The consequences of inappropriate aggregation will be demonstrated using the 1985 federal grazing fee study conducted by the Forest Service and the Bureau of Land Management, as mandated by section 12b of the Public Rangelands Improvement Act of 1978. The results of this study were reported in a publication entitled 1985 Grazing Fee Review and Evaluation (USDI/ USDA 1985), which presents and analyzes several alternative grazing fee formulations. This analysis of grazing fee alternatives was based on data obtained from a market rental appraisal. The methodology for collecting and analyzing this data was contained in an appraisal report prepared by Tittman and Brownell (1984).

\section{Federal Grazing Fee Study}

The data used in the federal grazing fee study were collected by field appraisers who interviewed an estimated 100,000 persons during the 17 -month period from July 1982 to November 1983. These interviews resulted in 7,246 usable observations of different prices reflecting the results of open market negotiations between lessors and lessees for grazing use of lands by cattle, horses, yearling cattle and sheep. Data on 99 physical characteristics and lease

\footnotetext{
2The PRIA formula is as follows:$$
\text { Fee } t_{t+1}=\$ 1.23 \times \frac{\text { FVI }_{\mathrm{t}}+\left(\mathrm{BPI}_{\mathbf{r}} \mathrm{PPI}_{\mathrm{t}}\right)}{100}
$$$$
\text { where: } F e e_{t+1}=\text { grazing fee to be paid }
$$$$
\mathrm{FVI}_{\mathbf{t}}=\text { forage value index }
$$$$
\mathrm{BPI}_{\mathbf{t}}=\text { beef price index }
$$$$
\mathrm{PPI}_{\mathrm{t}}=\text { prices paid index. }
$$ 
terms and conditions that could affect value were collected for each lease. The appraisal covered 16 western states plus 2 counties in Texas, which were divided into 6 pricing areas (Fig. 1). It is not clear in the federal study how or why these pricing areas were developed.

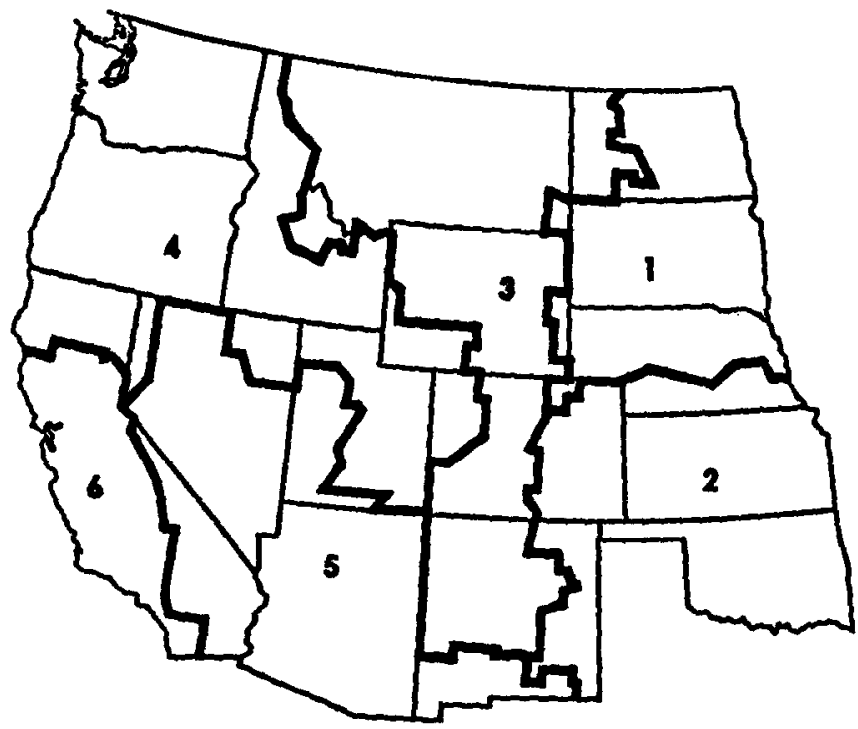

Fis. 1. Pricing regions of the federal grazing fee study.

\section{Testing for Homogeneity}

Average lease prices determined in the grazing fee study are summarized in Table 1 . In the study, these averages were not tested for homogeneity between regions. ${ }^{3}$ One method that could have

Table 1. Grazing lease price data by regions used in the federal grazing fee study.

\begin{tabular}{cccc}
\hline Pricing region & $\begin{array}{c}\text { Average } \\
\text { (\$/head/month) }\end{array}$ & $\begin{array}{c}\text { Standard } \\
\text { deviation }\end{array}$ & $\begin{array}{c}\text { Number of } \\
\text { observations }\end{array}$ \\
\hline West & $\begin{array}{c}\text { Non-federal Leases } \\
1\end{array}$ & 4.65 & 4,427 \\
1 & 7.25 & 5.57 & 387 \\
2 & $10.07^{\mathrm{a}}$ & 4.20 & 596 \\
3 & $7.34^{\mathrm{b}}$ & 4.60 & 1,334 \\
4 & $7.57^{\mathrm{b}}$ & 4.43 & 1,188 \\
5 & $6.51^{\mathrm{c}}$ & 4.27 & 300 \\
6 & $5.75^{\mathrm{d}}$ & 4.28 & 622 \\
& $6.86^{\mathrm{c}}$ & & \\
West & Federal Leases & & \\
1 & $7.15^{2}$ & 5.06 & 44 \\
2 & $8.98^{\mathrm{a}}$ & 4.66 & 34 \\
3 & $6.85^{\mathrm{b}}$ & 2.54 & 386 \\
4 & $7.10^{\text {bc }}$ & 3.77 & 280 \\
5 & $7.83^{\text {abed }}$ & 6.93 & 39 \\
6 & $5.32^{\mathrm{e}}$ & 3.21 & 39 \\
\hline
\end{tabular}

Source: Appraisal report Estimating Fair Market Rental Value of Grazing On Public Rangelands (Tittman and Brownell 1984, appen. 13, p. 12).

'Non-federal leases represent market transactions for land which is primarily privately owned.

${ }_{2}^{2}$ Federal leases represent federal land subleases, federal land put up for competitive bid, or federal land priced according to comparable private leases.

${ }^{3}$ Any two means followed by the same letter are not significantly different at the $10 \%$ level of probability.

3The federal study did recognize that differences exist in grazing lease prices between regions. On page 10 of the study (USDA/USDI 1984) the statement was made: “The analysis showed there were different prices being paid for different kinds and types of animals. They also showed there were differences in prices being paid in different geographic areas that could be attributed to broad differences in various factors that include location, season of use, and carrying capacity or quality of range." This observation did not lead the researchers to the important implication for the need for a variable grazing fee. been used to check for homogeneity would have been to test whether the mean prices in the 6 regions were significantly different using a one-way analysis of variance (ANOVA). If these 6 mean prices are not significantly different, it is reasonable to aggregate to a single uniform figure that can then be used in the analysis.

A one-way ANOVA is an appropriate statistical method to use when there are unequal sample sizes. The null hypothesis $\left(\mathrm{H}_{0}\right)$ for testing for differences in average lease prices between regions was formulated as $H_{0}: \mu_{1}=\mu_{2}=\mu_{3}=\mu_{4}=\mu_{5}=\mu_{6}$. Analysis of variance on the non-federal lease data resulted in an F-value of 45.176 , which resulted in rejection of the null hypothesis of equal means at the $\alpha=0.0001$ level. Analysis of variance on the federal lease data resulted in an F-value of 5.796 . In this case the null hypothesis of equal means was rejected at the $\alpha=0.001$ level. Since in both cases the null hypothesis was rejected, a pair-wise comparison was conducted for both the non-federal and federal leases to determine which, if any, regions were similar. The comparisons are presented in Table 1 and indicate at least 4 distinct pricing regions.

With these regional price differences, implementation of a uniform grazing fee for all western states that collects full market value of the forage would result in an inequitable distribution of impacts upon individuals within the range livestock industry. These inequitable impacts would subsidize some and damage others.

The draft federal grazing fee study did use the lowest average forage value from pricing region 5 in their example and subsequent impact analysis. However, there were no assurances given that this lowest figure would be used in final fee formulations. Furthermore, even if this lowest value were used in setting grazing fees in the future, closer analysis of the data indicates an inappropriate policy would arise. A uniform grazing fee is a policy that attempts to describe and treat the typical individual where no such typical individual exists. Only a variable fee is statistically defendable based upon data collected for the federal grazing fee study. This is a different conclusion than that of the 1966 grazing fee study where no regional pricing differences could be found and the data supported a uniform fee.

\section{The New Mexico Comparison}

Additional exemplification of inappropriate aggregation in the federal grazing fee study can be obtained by comparing the results of the federal study to results obtained from a New Mexico State University (NMSU) state lands grazing fee study (Fowler et al. 1985). The comparison is particularly germane because 3 of the 6 federal pricing regions converge in New Mexico, and are similar to pricing regions used in the comparable state land study.

The opportunity for analysis and comparison presented itself when the New Mexico State Land Commissioner decided to use private market lease rates for rangeland as a basis for determining lease rates for state trust land, and to use the federal grazing fee study as a primary data base. Four counties were omitted from the federal study because of the absence of federally owned land. The state land study was designed to interview the four omitted counties with exactly the same research format as used by the federal study. The data was to be pooled with the federal data and the combined data base was to be used to determine the price structure for leasing state trust lands. When the federal government was unable to release their data on the remaining 29 New Mexico counties in a timely manner, because of the political sensitivity of the data, it was decided to interview the remaining 29 counties. The result was a complete data base for New Mexico, collected in the same research format as the federal study and over the same time frame. The 651 private lease observations collected in the state land grazing fee study for the lease year 1983-84 exceeded the 296 comparable observations collected for New Mexico in the federal grazing fee study.

The 3 pricing regions used in the state land grazing fee study are shown in Figure 2 as well as the average lease price for each 


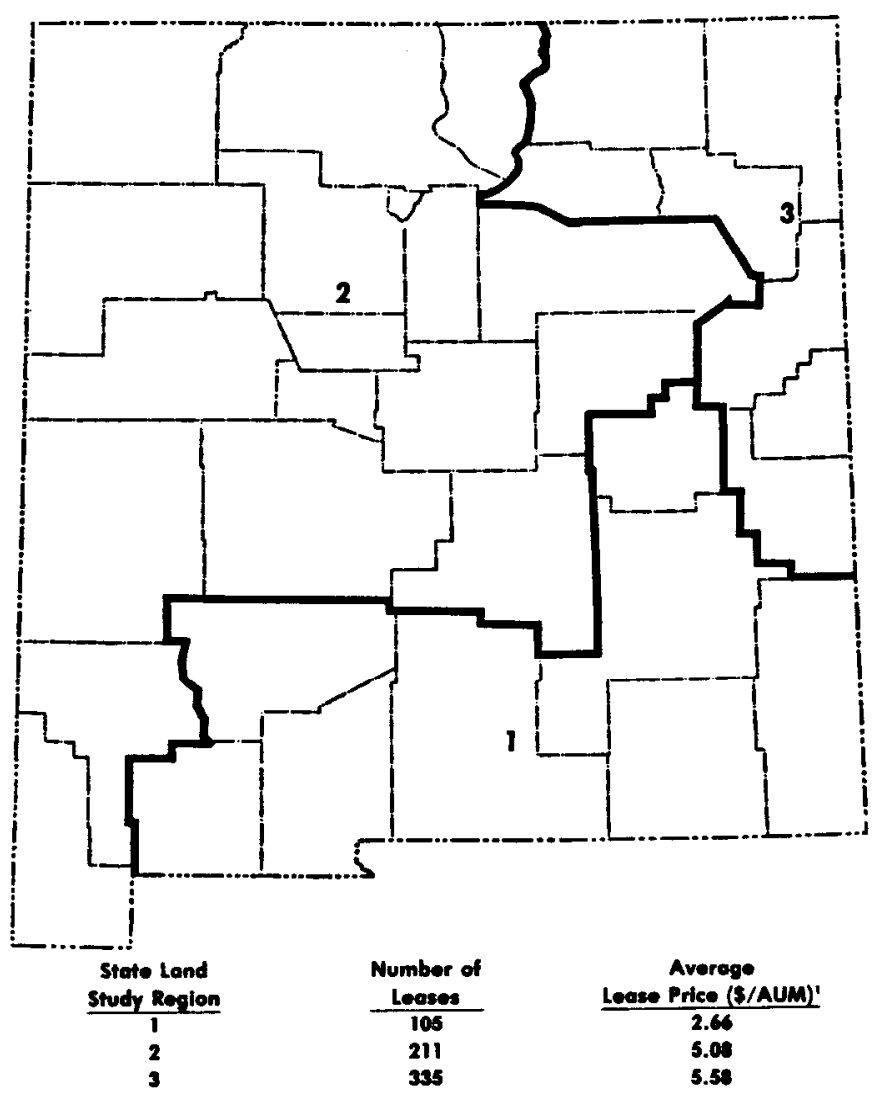

'Source: Torell 1935.

Fig. 2. Average lease price per $A U M$ by pricing region, state land grazing fee study.

region in dollars per animal unit month (AUM). ${ }^{4}$ The three pricing regions in the state study were determined by statistically comparing the average lease price between counties. There were no statistically significant differences within the pricing regions and the differences between regions were significant at the $\alpha=0.01$ level. These regions closely approximate the New Mexico portion of the 3 regions determined in the federal study (Fig. 1). Region 3 of the federal grazing fee study was quite comparable to region 2 of the state land grazing fee study. Only 2 counties (Grant and Hidalgo) were omitted and these were placed in federal study Region 5. Region 2 of the federal grazing fee study accurately picked up the highly productive northeastern counties of New Mexico; however, it included 3 counties (Chavez, Lea, and DeBaca) from the southeast which the state land grazing fee study indicated should be in a different region. Overall, pricing area designations between the 2 independent studies were similar.

A comparison of the lease prices within the comparable regions of the $\mathbf{2}$ studies reveals some striking differences. In the state study, the average lease price for region 3 is more than twice as large as that for region 1 (Fig. 2). This large difference in average lease price between regions is not reflected in the federal study (Table 2). Additionally, in the state study the average lease price in region 3 is greater than that for region 2 , while the reverse is true in the federal study.

These results indicate how misleading the data from inappropriate aggregation can be. The average lease price for region 3 of the

The data presented in Table I from the federal study included only mature animal (cow/calf pairs, dry cows, unspecified cattle types, horses, and bulls) with 1922 leases providing grazing lands for yearlings and sheep excluded (Tittman and Brownell 1984, Appen. 13, P. 4). The state land grazing fee study includes all livestock classes including yearlings (no sheep were included). The data in the state study were made comparable with that presented in the federal study by adjusting by the animal unit equivalency conversion factors presented in the federal appraisal report (Tittman and Brownell 1984, Appen. 11, P. 5).
Table 2. Average lease price in dollars per head per month by pricing region, federal grazing fee study.

\begin{tabular}{ccc}
\hline \hline Federal study region & $\begin{array}{c}\text { From clipped data } \\
(\$ / \text { hd } / \text { mo })\end{array}$ & $\begin{array}{c}\text { From unclipped data } \\
(\$ / \text { hd } / \text { mo })\end{array}$ \\
\hline 2 & 7.50 & 7.34 \\
3 & 8.00 & 7.57 \\
5 & 5.50 & 5.75 \\
\hline
\end{tabular}

In the federal study the original data were clipped to eliminate excessive variation in the data. Clipping retained only observations within one standard deviation of the mean price in each pricing area. We contend that this practice of clipping is no statistically valid and represents another serious flaw in the federal grazing fee study. This data is reported on page 31 of 1985 Grazing Fee Review and Evaluation draft report.

federal study, which includes the central and northwestern corner of New Mexico, is heavily influenced by data obtained from Montana, North Dakota, Wyoming, and Colorado. The average lease price for region 2 of the federal study, which includes the eastern portion of New Mexico, is heavily influenced by data obtained from eastern Colorado, southern Nebraska, Kansas, and Oklahoma. The influence of these other states distorts the pattern that is observed when New Mexico is treated independently as it was in the state lands grazing fee study.

Comparison of the federal grazing fee study with the New Mexico study indicates the 6 regions used in the federal study are not defined narrowly enough to achieve homogeneity within regions. If average lease prices are correct in both studies, the implication is that New Mexico does not belong in any of the $\mathbf{3}$ federal pricing regions that converge in the state. In each of the comparable regions, average market rates observed in the New Mexico study are about $\$ 2$ per AUM less than levels reported for the federal study.

\section{Conclusions}

Statistical analysis of the data used as the basis for the federal grazing fee study shows the data on lease prices are not homogeneous throughout the west. Further, comparison of the federal grazing fee study with a similar New Mexico grazing fee study indicates the regions used in the federal study are not homogeneous, even within regions. Proper policy formulation requires the total data set be divided into groups which are homogeneous, and that a series of grazing fees be implemented with a separate grazing fee for each homogeneous region. Failure to follow accepted statistical procedures in aggregating data will result in a policy that neither recognizes nor adequately treats the highly divergent enterprises that comprise the western range livestock industry. If grazing fees are significantly increased, this will create an economic environment that will make it difficult for some enterprises to survive and will, at the same time, provide a subsidy to others.

\section{References}

Fowler, J.M., L.A. Torell, J.M. Witte, and R.D. Bowe. 1985. Grazing transactions in New Mexico 1983-84, implications for state trust land grazing fees. New Mexico Coop. Ext. Serv. Range Impr. Task Force Rep. 18.

Nielsen, D.B. 1972. Economic implications of variable versus single grazing fees. J. Range Manage. 25:2-6.

Obermiller, F.W. 1984. Economic theories, p. 27-46. In: J.H. Smits (ed.). Federal grazing fees: What is "Fair Market Value?". Public Lands Committee, National Cattlemen's Association, Washington, D.C.

Torell, L.A. 1985. Federal land grazing fees: Nobody's satisfied. AgriCents. New Mexico Coop. Ext. Service. June issue.

Tittman, P.B., and C.E. Brownell. 1984. Appraisal report estimating fair market rental value of public rangelands in the western United States. Administered by USDA - Forest Service and USDI - Bureau of Land Management. U.S. Department of Interior/U.S. Department of Agriculture. Washington, D.C.

U.S. Department of Agriculture-Forest Service and U.S. Department of Interior-Bureau of Land Management. 1985. Grazing fee review and evaluation. Draft Report. Washington, D.C. 